\title{
Un vistazo general a los Principios Latinoamericanos de Derecho de los Contratos*
}

\section{1) Carlos Pizarro Wilson ${ }^{*}$}

Resumen. Este trabajo expone los resultados del grupo de investigación que creó los Principios Latinoamericanos de Derecho de los Contratos. Explica la creación del grupo de profesores investigadores que discutieron y redactaron el texto, presenta la metodología y analiza los principales aspectos del texto, en lo relativo a la noción del contrato, la formación, el cumplimiento y el incumplimiento.

Palabras clave: derecho de los contratos, armonización contractual, derecho privado.

\section{Overview of Latin American Principles of Contract Law}

Aвstract. This paper seeks to show the results of the research group that created the Latin American Principles of Contract Law. It explains the creation of the group of research professors who discussed and drafted the text, clarifying the methodology and presenting the main aspects of the text, regarding the notion of contract, training, compliance and non-compliance.

Fecha de recepción: 13 de abril de 20I8. Fecha de aceptación: I4 de mayo de 2018.

Para citar el artículo: Pizarro Wilson, C., "Un vistazo general a los Principios Latinoamericanos de Derecho de los Contratos", Revista de Derecho Privado, Universidad Externado de Colombia, n. $^{\circ} 35$, julio-diciembre de 2018 , 35 I-368. Dor: https://doi.org/IO.I860I/or $234366 . n 35.13$ Véase la página oficial de los Principios Latinoamericanos del Derecho de los Contratos: http:// pldc.uexternado.edu.co

** Doctor en Derecho por la Universidad Paris II Panthéon-Assas. Profesor de Derecho Civil de la Universidad Diego Portales y de la Universidad de Chile, Santiago de Chile, Chile. Contacto: carlos.pizarro@udp.cl 
KeYwords: Contract Law, contractual harmonization, Private Law.

Sumario. Introducción. I. El origen y desarrollo del proyecto. ir. La noción de contrato. III. Formación del contrato. iv. Cumplimiento e incumplimiento. Conclusión. Referencias.

\section{Introducción}

El derecho de los contratos ha tenido una transformación relevante en diversas latitudes ${ }^{\mathrm{I}}$. La región latinoamericana no ha sido la excepción, aunque los esfuerzos de codificación han sido más bien mezquinos. Salvo por la reciente codificación argentina, el impulso ha venido de trabajos doctrinales, entre los cuales debemos destacar la labor del grupo dedicado a la elaboración de los Principios Latinoamericanos de Derecho de los Contratos (PLDC).

Este trabajo pretende explicar brevemente el proceso de elaboración de los principios, así como la metodología de trabajo, mediante la descripción de cada una de las etapas del proceso, las motivaciones, los desafíos y las reflexiones al interior del grupo sobre aspectos problemáticos. El análisis se concentrará de manera especial en la noción de contrato, que aparece como esencial en los Principios, pero también abordaremos, aunque sea en forma panorámica, las cuestiones centrales del articulado, referidas a la formación, el cumplimiento y el incumplimiento.

\section{El origen y desarrollo del proyecto}

El origen del proyecto está en el trabajo realizado por un grupo de profesores de distintos países de Latinoamérica: Argentina, Brasil, Uruguay, Chile, Colombia, Paraguay, Guatemala y Venezuela ${ }^{2}$. Se trata de un proyecto ambicioso, que bajo el alero de distintas universidades y con el valioso apoyo de la Fondation pour le Droit Continental (Francia) produjo, luego de siete años de trabajo, I 23 artículos que abarcan todo el espectro del derecho de los contratos.

I Una panorámica general en Pizarro Wilson, C. (coord.), El derecho de los contratos en Latinoamérica. Bases para unos principios de derecho de los contratos, Bogotá, Universidad del Rosario y Universidad Externado de Colombia, 20 I 2.

2 A nivel institucional merece destacarse el apoyo directo e indirecto de las universidades de los profesores miembros del grupo. Me refiero a las universidades colombianas Externado de Colombia y del Rosario, quienes nos acogieron en reiteradas oportunidades. También a la Universidad de Buenos Aires, donde se realizó uno de los encuentros. Y debo extender los agradecimientos a la Pontificia Universidad Católica de Valparaíso y a la Universidad Diego Portales, que contribuyeron a la organización y acogida de otros tantos encuentros. Se agradece, por último, la fraternidad de las universidades de la República (Uruguay) -y a su núcleo de derecho civil-, Central de Venezuela y Francisco Marroquín de Guatemala. Sin la generosidad de todas estas instituciones la tarea no habría sido posible. 
La iniciativa comenzó a gestarse en el curso de un congreso internacional franco-latinoamericano realizado en la ciudad de Rennes y organizado por el profesor Thomas Genicon. En esa oportunidad se avanzó la idea de comenzar a reunirse para discutir la viabilidad de redactar los mencionados Principios. Con gran entusiasmo, el profesor Michel Grimaldi, director académico de la Fondation pour le Droit Continental, apoyó el proyecto, lo que nos permitió, durante años, realizar encuentros periódicos o sesiones de trabajo.

Dichas sesiones, en una primera etapa, se organizaron en mesas temáticas dedicadas a la elaboración de un diagnóstico general del estado de la cuestión en la región, y luego a la preparación, a partir de un cuestionario, de propuestas de articulado que se fueron discutiendo en asamblea hasta lograr una redacción consensuada y definitiva.

En un comienzo pudimos constatar que en Latinoamérica los derechos en el ámbito de los contratos son bastante desiguales, en términos de regulación propios del sistema continental, en los códigos civiles, pero también, y quizá aún más, en la legislación especial y, en consecuencia, en la aplicación por los tribunales y la comprensión doctrinal de las cuestiones centrales. Es fácil percatarse de la diversidad no solo de fuentes, sino de épocas a que responden los derechos nacionales. De ahí que el objetivo no podía ser plantear un código modelo o una idea de uniformidad del derecho de los contratos. Por ello se pensó en que los Principios sirvieran de modelo para reformas en países que lo ameriten, por ejemplo Chile y Colombia, y en que en otros casos permitieran inspirar mejores soluciones judiciales y arbitrales a título de lex mercatoria. No se busca una iteración de otros principios o procesos de armonización contractual. El objetivo de este trabajo académico fue proponer un modelo de reglas que permitan inspirar reformas legales necesarias en la región en el área sensible de los contratos, pero también, que con base en ellas se puedan resolver conflictos que se susciten en contratos internacionales de la región latinoamericana. Para llevarlo a cabo se intentó dar una cierta identidad al trabajo académico, lo que no fue fácil, no solo por las tradiciones locales, sino también por la formación jurídica de los miembros del grupo. Un fantasma recorría el grupo: ¿de qué manera el trabajo que llevaríamos a cabo debería apartarse de la uniformidad de esos textos de compromiso entre dos familias del derecho de los contratos, el common law y el derecho continental? Esto nos impulsó durante todo el proyecto a interrogarnos acerca de la supuesta identidad del derecho de los contratos en Latinoamérica, o al menos en los países que tienen profesores en el grupo de trabajo. Esa identidad ha sido esquiva, en el sentido de que los códigos civiles de la región, e incluso los más recientes o aun un código fresco, como el argentino, reciben distintas influencias del derecho europeo. Aún más, una tensión constante en el grupo ha sido reflejada por la formación académica de los profesores, quienes han obtenido sus doctorados en distintos países: Italia, Holanda, Francia y España, en lo fundamental. Uno podía pensar en mirar la "jurisprudencia” de estos países. 
Desde el punto de vista metodológico, uno de los primeros trabajos que realizamos fue un diagnóstico a partir de un cuestionario que permitiera conocer el estado de la doctrina y la jurisprudencia de cada país. Un insumo valioso, pero insuficiente, pues las diferencias entre los autores, y la inconsistencia de los fallos, no alentaban una búsqueda de coherencia por ese camino. A esto cabe agregar la influencia más o menos intensa de los tribunales constitucionales en los aspectos patrimoniales del derecho civil. Esa identidad errática nos llevó a buscar en nuestros códigos y proyectos de reforma, locales y extranjeros, normas que satisfagan un derecho de contratos adaptado para el comercio actual en la región. Nuestro anhelo fue mantener en lo que nos une, aquello que compartimos, que nos identifica y que funciona de manera adecuada; innovar en aquellos aspectos en los que carecemos de normas o en los que parece necesario impulsar un cambio. Es esa tensión, en la búsqueda de un trabajo original, que no sea una simple copia de otros proyectos de armonización, lo que ha marcado nuestra tarea. Hemos tratado de avanzar en un texto auténtico que recoja nuestra tradición, y en aquellos aspectos en que hemos estimado necesario innovar nos hemos inspirado en variados modelos, incluyendo la propuesta de reforma española al derecho de las obligaciones, el proyecto de código civil argentino, las propuestas de reforma y la reforma misma al derecho de las obligaciones en Francia, así como instrumentos de soft law como los pecl y los Principios Unidroit, además de nuestros códigos civiles.

Es cierto que los debates, por momentos arduos, se vieron facilitados por un idioma común y por el respeto y la amistad que animaba a los miembros. La elaboración permitió rescatar elementos que para el grupo eran compartidos y, por lo mismo, conocidos, tanto en el lenguaje como en la comprensión de ciertas instituciones.

Un ejemplo, con un debate significativo, fue la decisión de conservar o no la causa como elemento esencial del contrato, lo que, reviviendo un inveterado debate doctrinal, significó mantenerla, siendo aún en la región latinoamericana un requisito transversal de los contratos y, más allá, un instrumento eficaz de control y justificación de variadas instituciones del derecho contractual.

¿Qué razones apoyaron su conservación? La tradición, en primer lugar, en cuanto constituye un elemento de existencia del contrato y, además, de licitud en la mayoría de los sistemas de la región. Sin duda una institución vieja como la causa -presente en manuales, monografías, fallos y, en general, en el ethos de la cultura jurídica- parecía difícil de borrar; o, al menos, para varios de los representantes del grupo, resultaba osado pensar en excluirla de un modelo de derecho de los contratos. Pero es cierto que la tradición no es un argumento suficiente, y por eso la búsqueda de su utilidad fue parte del debate y, por cierto, el mejor argumento para mantenerla.

¿Qué utilidad tiene o ha tenido la causa en el espectro latinoamericano? Para esto debe distinguirse, como lo hacen los Principios, entre la causa de la 
obligación y aquella del contrato. En cuanto a la primera, ha sido un mecanismo de control del equilibrio contractual. En Chile, Colombia y Argentina, al menos, se ha recurrido a la causa de la obligación para efectuar un control de la conmutatividad de las prestaciones, a propósito de cláusulas penales excesivas u otros fenómenos de desproporción entre las prestaciones. La causa de la obligación exige un equilibrio contractual, cuya ruptura comporta la ineficacia de la cláusula mediante la cual se determina el desequilibrio. En Colombia, entre otras aplicaciones, se ha recurrido a ella para explicar los grupos de contratos y los efectos de ineficacia de uno de los contratos que forman parte del grupo en el resto. Así también ha ocurrido en Argentina. En las cadenas de contratos y los grupos de contratos u otros montajes contractuales la causa permite explicar las repercusiones de un contrato en los demás contratos que forman parte de la cadena o grupo respectivo. En Argentina, además de que el nuevo código la mantiene, en términos similares a la regla que se propone en los Principios, es decir, causa objetiva y subjetiva o causa de la obligación y del contrato. La causa permite anular un contrato cuando resulta frustrada por alteración de las circunstancias existentes en el momento de contratar o para acoger la teoría de la imprevisión. El fundamento es la causa de la obligación. También se ha utilizado para explicar las restituciones consecutivas a la resolución, en razón de que se genera un pago de lo no debido, concurriendo una ausencia de causa que lo justifique. En fin, lejos de lo que se piensa, la causa goza de buena salud en los países de la región latinoamericana. Así lo muestra la jurisprudencia de nuestros países. A lo anterior se agrega su uso como control moral del contrato, al atacar los motivos ilícitos del mismo. Acá se trata de la causa del contrato.

Luego, la pregunta que se hace la mayoría es si resulta suficiente que puedan lograrse mediante otros medios estos fines que han sido obtenidos a través de la causa. Es suficiente que se pueda recurrir al "objeto" o "prestación" del contrato para algunos, o a la idea de "equilibrio del contrato" para otros, o a la voz "contenido del contrato" u "objetivo". Como se ha sugerido, parafraseando al profesor Genicon, sabemos que las palabras no son inocuas, y más aún cuando las utiliza el legislador: solo al comienzo aparecen como neutras, pero luego hay que dotarlas de contenido, de aplicación. ¿Por qué rechazar una tradición y explicación decantada a propósito de este elemento del contrato? ¿Por qué recurrir a una explicación a través de otro elemento, como el objeto u otras nociones desconocidas para nuestros derechos, y olvidar lo avanzado y aplicado a través de la noción de causa? ¿Qué razón hay para excluir una palabra "cargada de experiencia social”? A través de esta expresión los juristas latinoamericanos nos comunicamos, entendiendo más o menos lo mismo una vez pronunciada ${ }^{3}$. En ningún caso correspondía excluirla. La posición por la exclusión, a título

3 Genicon, Th., "Défense et illustration de la cause en droit des contrats, du régimen general et de la preuve des obligations", Dalloz, 2015, n. ${ }^{\circ} 27$, I 55 I ss. 
personal, me pareció más bien academicista que práctica. A través de la causa se logra en el derecho de los contratos una explicación armónica durante su fase de formación y ejecución. Por esto, el grupo decidió mantener la "causa".

Así también ocurrió con la pervivencia de la nulidad absoluta y relativa o anulabilidad, que va asociada a la introducción de dichos elementos esenciales, lo que sin duda constituye una novedad en los PLDc. Si bien no se nos escapa que es difícil aceptar la introducción de elementos esenciales del contrato y la consecutiva sanción de nulidad absoluta, dado el carácter dispositivo de los Principios, el hecho de que deba servir de modelo de armonización permite asumir este riesgo y desliz en su formulación.

Todos estos debates, que entrecruzan cuestiones clásicas, pero otras, según veremos, más cercanas, reflejan que el derecho de los contratos en la región ha padecido un cambio significativo desde la época de la codificación, de la mano de la consolidación de los Estados nacionales. Sin duda, en esa época el derecho civil en los códigos fue un símbolo de identidad nacional, produciéndose hasta la actualidad un decaimiento de la impronta, que se nutre de variadas influencias y, por qué no decirlo, de una tendencia más bien a la homogeneidad del derecho de los contratos 4 . Ese ha sido el trayecto en Europa, donde los esfuerzos por aunar el derecho, aunque no en forma total, han ido desencadenando un derecho de los contratos en que las coincidencias son mayores que las diferencias, incluso entre la familia del common law y del derecho continental. Como lo ha sugerido el profesor Peña: “¿Por qué no podría ocurrir que la globalización económica estuviera acompañada del fenómeno inverso: no de la consolidación de derechos nacionales, sino de su homogeneización, y por esa vía de la lenta disolución de sus límites?" 5 . Esta pregunta, esencial, que ha sido una espina constante en la elaboración de los Principios, nos ha llevado a afirmar, en el puñado de artículos que presentamos, una cierta homogeneidad, pero en ningún caso total.

$Y$ es ese resultado lo que ahora exponemos, como guía para futuras reformas a nuestros códigos civiles y como modelo de resolución de conflictos, así como para avanzar hacia una lex mercatoria latinoamericana. No es posible excluirse de ese proceso de uniformización del derecho, pero tampoco debe caerse en la banalidad de la homogeneidad de un derecho común sin contrastes, lo que comportaría un sacrificio cultural innecesario. Lo que proponemos, entonces, es un derecho común de los contratos, orientado de acuerdo con las tendencias del nuevo derecho de la contratación, pero sin renunciar a ciertos particularismos propios de la tradición y de la práctica del derecho en la región. El derecho de

4 Cafaggi, F., "Los nuevos fundamentos de la regulación privada transnacional", en Revista de Derecho Privado [online]. 20I4, n. ${ }^{\circ}$ 26, I 85-2 I 7, disponible en: http://www.scielo.org.co/scielo. php? script=sci_arttext\&pid=So I 23-436620 I 4000 I $00006 \& \operatorname{lng}=$ en \&nrm=iso [consultada el 30 de octubre de 20I7].

5 Peña González, C. "La unificación de principios en el derecho latinoamericano", 20 I4, inédito. 
los contratos en Latinoamérica ha sido y sigue siendo receptivo frente a normas y tradiciones que vienen de Europa, y ahora, sin duda, se ha presentado, también, una cierta "americanización" del derecho de los contratos, con gran énfasis en la técnica contractual, lo cual no ha estado exento de problemas con la traducción de cláusulas tipo de los contratos angloamericanos, y frecuentes ya en los de la región, pero cuyo encaje local no se hace sin problemas. Así ocurre, por ejemplo, con las cláusulas de indemnidad o no solicitation. Me refiero, claro está, a Estados Unidos y su influencia en el ámbito de la contratación internacional. Sin contrapeso la técnica contractual, y con esto aludo a la manera como se escriben los contratos internacionales, van de la mano del derecho estadounidense. Menos derecho supletorio y más cláusulas contractuales, esa es la práctica en los contratos comerciales internacionales y, en no pocos casos, en los contratos más importantes desde el punto de vista económico en los países latinoamericanos en que han proliferado los estudios de abogado a la usanza de Estados Unidos.

El sesgo propio del derecho continental, en el sentido de que el contrato mantenga sus silencios para que el legislador complete las lagunas, en forma imperativa o nada más supletoria, se entiende como un riesgo, no como una ventaja. ¿Acaso Bello no adelantó un esfuerzo de recepción del derecho común europeo en el código civil más relevante en Latinoamérica? ¿Por qué no atenernos simplemente a esta nueva tendencia y volver a ser recipientes de un cierto derecho común europeo, o dejarnos tentar por el derecho norteamericano, tal como ha ocurrido en algunas materias a nivel normativo? Piénsese en el fideicomiso con autonomía de patrimonios (trust), o en el deber de mitigar el daño en lo contractual e incluso, más allá, en lo extracontractual. ¿ Si Keleman se ha planteado la interrogante acerca de la "americanización" del derecho europeo y japonés, no sería lo nuestro, más bien, una manera indirecta de introducir tendencias europeas $^{6}$ ? Varias de estas cuestiones o preguntas rondan las observaciones del profesor Hugh Beale 7 .

El grupo de trabajo y los Principios que presentamos son un esfuerzo deliberado y consciente de plantear un derecho de los contratos uniformes que inspire las soluciones legales atado a una identidad cultural, que escape a esa tendencia de homogeneidad sin matices que aspira a un derecho global sin considerar

6 Kelemen, D. y Sibbitt, E. C. “Lex Americana'. A response to Levi Faur”, 2005, disponible en: http://fas-polisci.rutgers.edu/dkelemen/research/kelemen-sibbitt_lexamericana.pdf Destaco la tesis de estos autores, criticada por Levi Faur, al señalar: "In a liberal economy with a multiplicity of players and few encompassing trade associations, informal, cooperative, and flexible approaches to regulation are ineffective. Political fragmentation further undermines such approaches and creates incentives for governments to mandate broad transparency and to empower private actors to enforce regulatory policies. Thus, when new policy demands are fltered through a system that combines a liberalized economy and political fragmentation, an American style approach to regulation is likely to result" (p. 469).

7 Beale, H., "The Principles of Latin American Contract Law: A response from an outsider", en Momberg, R. y Vogenauer, S. (eds.), The future of Contract Law in Latin America. The Principles of Latin American Contract Law, Bloomsbury-Hart, 201 7, 265 ss. 
aquellos signos distintivos de las sociedades. No es, en consecuencia, una mera cuestión funcional o instrumental orientada a la solución de conflictos contractuales, sino que hemos buscado recoger esas particularidades que en el derecho de los contratos podamos encontrar en la región. Esto, a pesar de la pluralidad de influencias foráneas, y no pocas veces de una genuina miscelánea normativa. El éxito de los Principios, además, dependerá, en gran medida, de su difusión y activa penetración en el foro legal a través de abogados en los países que poco a poco, pero en forma persistente, vayan formando ese derecho común a título de lex mercatoria. En esta tarea será fundamental el rol de la universidad, por intermedio de sus académicos, para permitir la expansión y conocimiento de los Principios hasta convertirlos en un instrumento al cual recurran los abogados no solo como argumentos a fortiori, sino como una especial y fundada forma de resolver los conflictos contractuales.

A diferencia del siglo xıx, cuando la influencia del derecho francés y aun más del código civil francés era incontrastable, en la actualidad las influencias en la región latinoamericana son plurales y el panorama del derecho de los contratos en la región es bastante disímil ${ }^{8}$.

Por ejemplo, hoy Argentina goza de un nuevo código civil donde las fuentes son bastante plurales, y, con un planteamiento propio de la década de i 980 , unificó el régimen de responsabilidad civil contractual y extracontractual. Es cierto que no puede torcerse la particularidad del contrato, y por eso la regla de la previsibilidad para la medida de los daños persiste, tal como apareciera ya en la obra de Pothier hace trescientos años. En cambio, el derecho colombiano vive un fortalecimiento de la protección del consumidor, dictándose solamente en el año 20 I 2 una ley de protección a los derechos de los consumidores, existiendo desde hace bastante tiempo una modernización del derecho de los contratos, a través de las reformas introducidas al código de comercio a partir de la década de i970. A su turno, el caso venezolano es el símbolo del dirigismo contractual, el Estado interviene los contratos fijando precios y reduciendo la libertad contractual a una mera quimera. Chile, en cambio, en este ámbito, muestra una legislación inmutable en el tiempo, que refleja la delicuescencia del modelo decimonónico del derecho de los contratos y que solo logra, con el esfuerzo de la doctrina local, ir transformando el derecho paso a paso, a través de la jurisprudencia, de manera que con unas mismas reglas decimonónicas se alcance un derecho adaptado a las necesidades contemporáneas. Las mismas reglas gobiernan el derecho de los contratos desde el siglo xix, con las lagunas y vacíos que la doctrina propone resolver por vía de la interpretación e integración contractual. Una revisión de la situación en la región muestra procesos o anhelos de reforma, y en el caso chileno un derecho de los contratos que ya no se explica por los códigos, sino

8 Cfr. Momberg, R. "The process of harmonization of Private Law in Latin America”, en MomBerg y Vogenauer, ob. cit., 3 . 
más bien por las opiniones de los autores y la jurisprudencia, lo que resta en gran medida una de las fortalezas del derecho continental.

\section{La noción de contrato}

Referirse a la noción de contrato es una tarea espinosa y en gran medida fluctuante por el hecho de encontrarse sometida a diversas concepciones políticas y económicas. El contrato en cuanto fuente de obligaciones determina a qué se obliga el deudor, aunque el artículo que lo define (art. 8) es más bien una descripción que alude a la necesidad del acuerdo y el efecto de este, lo que muestra una definición que está lejos de ser rígida, sin que pueda, en todo caso, extrapolarse una noción precisa. Debe considerarse lo relativo a los principios generales que el grupo definió: la libertad contractual, la fuerza obligatoria y la buena fe. En consecuencia, es preciso reconocer la libertad de los contratantes para celebrar los contratos y fijar su contenido, con los límites usuales, esto es, no solo el orden público o el derecho ajeno, sino también la buena fe, principio transversal a todos los principios. Y se recoge, por último, la obligatoriedad del contrato (art. 6), que sin duda constituye un pilar de la contratación, pero no debe perderse de vista el control al cual queda sometida esa obligatoriedad, hecho a partir del cual es posible extraer la noción de contrato. El derecho de los contratos no puede entenderse sin afirmar la libertad de las partes para modelar su contenido, decidir su celebración y escoger al contratante; lo mismo ocurre con la fuerza obligatoria y el principio de la buena fe que, si bien pueden entrar en colisión a propósito del cumplimiento específico o la revisión por circunstancias sobrevinientes, implican que la palabra dada sea temperada, y en general, el derecho de los contratos se equilibre con el principio de la buena fe. Ahora bien, una de las preocupaciones de estos principios ha sido dotar de contenido a la buena fe, para que no sea un concepto amplio e inasible, dando ejemplos concretos de conductas que la contrarían y las consecuencias que acarrea su infracción. Así, verbigracia, en el caso de la responsabilidad precontractual, en que se reconoce el derecho a romper las negociaciones, pero si dicho retiro es contrario a la buena fe y causa un daño, este debe indemnizarse. Se ejemplifica indicando en el artículo ro la libertad en las negociaciones, una manifestación de la libertad de contratación: “(I) Las partes son libres de negociar el contrato y de retirarse en cualquier momento, pero esto y aquello deben hacerlo conforme a la buena fe". Y el artículo i i, al referirse al daño que merece indemnizarse, señala: "(I) El daño causado por el retiro de las negociaciones contrario a las exigencias de la buena fe debe ser indemnizado. (2) También es obligado a esta reparación el que inicia una negociación o se mantiene en ella sin ánimo o posibilidad de contratar. (3) En ningún caso se indemniza la pérdida de los beneficios esperados del contrato no celebrado". He aquí manifestaciones específicas de la buena fe para evitar el recurso a la misma en forma indiscriminada generando incertidumbre. 
Contribuye también a la comprensión de la noción de contrato lo que se expresa en los PLDC al referirse al "Cumplimiento como la ejecución del contrato en los términos en que fue acordado" (art. 77); lo que es refrendado por reflejo con la noción de incumplimiento (art. 86): "Concepto de incumplimiento. (I) Incumplimiento es la falta de ejecución del contrato en la forma pactada. (2) El cumplimiento imperfecto comprende toda disconformidad entre lo acordado y lo ejecutado por el deudor. (3) El incumplimiento del deudor comprende el hecho de las personas que emplee para la ejecución”. Se trata de uno de los asuntos que el grupo discutió con intensidad hasta concluir en la necesidad de una noción neutra del incumplimiento. Es esta idea la que atraviesa todo el articulado, erigiéndose en un pilar del sistema. De ahí que, por ejemplo, si el acreedor no recibe lo pactado o no se verifica un pago íntegro, habrá incumplimiento con independencia de la causa. Por lo mismo, si la causa es una imposibilidad debida a fuerza mayor hay incumplimiento, pudiendo reclamarse la resolución o la cesión de derechos, conforme lo dispuesto en el artículo artículo 90: "Imposibilidad total o parcial de cumplimiento. (I) La imposibilidad sobreviniente total y definitiva para cumplir una obligación contractual, causada por caso fortuito, extingue la obligación y libera al deudor. En tal caso, el acreedor puede optar por resolver el contrato o reclamar la cesión de los derechos y acciones que, en razón de la imposibilidad, el deudor detenta contra un tercero".

Para entender la noción de contrato que subyace a los PLDC es necesario considerar, además, algunos factores que permiten la intervención en su contenido o su extinción. El primero se refiere al tiempo en las relaciones contractuales. A diferencia del contrato en su fisonomía decimonónica, en el siglo xx una de las transformaciones cruciales en los acuerdos concierne a la duración en la ejecución de las obligaciones, lo que puso sobre el tapete la necesidad de abordar los cambios en las circunstancias de índole sobreviniente que alteran las previsiones y situación de las partes. El segundo aspecto se refiere a ciertos desequilibrios que, fuera del ámbito de protección del consumidor, reflejan una desigualdad en las relaciones contractuales que vale la pena considerar en las legislaciones contemporáneas atinentes al contrato. Si bien el artículo 8 no refleja una posición ideológica sobre lo que se ha entender por contrato, ciertas reglas permiten aseverar que el tiempo ha sido considerado como factor en la ejecución de las obligaciones y en el control de los desequilibrios entre las partes ${ }^{9}$. Bajo esa idea, también, deben evitarse referencias a los defectos o vicios del consentimiento y, con ello, aludir a los vicios del contrato, declinando una visión voluntarista propia de la ideología del codificador del siglo xIx. Al exponer los "vicios del contrato", el artículo 37, que lleva por título "Excesiva desproporción”, permite la adaptación del contrato o alguna de sus cláusulas, o incluso demanda la nulidad si nos encontramos frente a una "ventaja excesiva contraria a las exigencias de la 
buena fe". Existe ahí un repudio al desequilibrio del contenido del contrato que emana de una posición dominante de una parte respecto de la otra, estableciendo criterios que permitan al juez dirimir en qué casos corresponde calificar la situación como tal. No se nos escapa que la intervención del juez pueda aparecer desmedida, al facultarlo para "(4) adaptar el contrato a fin de ajustarlo al acuerdo que habrían alcanzado las partes conforme a la buena fe"; pero la justificación de esta injerencia parte de asumir un contrato que no merece ser obligatorio, dado el desequilibrio que proporciona a un contratante la ventaja desmedida frente al otro. Más allá de la perfección del contrato, circunstancias sobrevinientes pueden afectar el equilibrio, lo que permite la revisión del acuerdo. Esto se recoge en el artículo 84, relativo al "Cambio de circunstancias":

(I) Si, después de su celebración, la ejecución del contrato deviene excesivamente onerosa o su utilidad disminuye significativamente, por cambio de circunstancias cuyo acaecimiento o magnitud no pudo razonablemente haberse previsto y cuyo riesgo no fue asumido por la parte afectada, ésta puede solicitar a la otra la renegociación del contrato. (2) La renegociación no suspende la ejecución del contrato, salvo cuando ésta cause perjuicios irreparables para la parte afectada. (3) Si después de un plazo razonable las mismas partes no han adaptado el contrato, cualquiera de ellas puede solicitar al juez que lo adapte o resuelva, quien para hacerlo debe tener en cuenta la distribución de riesgos y costos que habían asumido las partes.

Pero no es la única regla que permite dejar sin efecto el contrato por una circunstancia sobreviniente. Los Principios admiten la frustración del contrato, inspirados en el artículo rogo del código civil argentino, lo que se recoge en el artículo 85 , aunque en forma más coherente se le intitula "De la frustración de la causa del contrato", entendida esta como el propósito práctico del contrato, desprovista de subjetivismos, indicando: "La frustración definitiva de la causa por un cambio de circunstancias existentes a la época de la perfección, imprevisto para las partes y que supera el riesgo asumido por aquella afectada, la autoriza a resolverlo".

\section{Formación del contrato}

A diferencia de lo que ocurre en los instrumentos internacionales usuales, el grupo decidió referirse a los elementos de la esencia del contrato, contemplando el consentimiento, el objeto, la causa y las solemnidades. Esto impactó en forma decisiva en la regulación de la nulidad, pues, a diferencia de aquellos instrumentos, se optó por mantener la nulidad judicial. Los sistemas regionales desconocen la nulidad por notificación, pero sobre todo pareció inadecuado que las partes pudieren, por su decisión, calificar la existencia o ilicitud de la causa y el objeto, 
determinando así la necesidad de la acción de nulidad. Dispone el artículo 9: "Elementos del contrato. Son elementos para la formación del contrato, el consentimiento, el objeto, la causa y en ciertos casos, la solemnidad”. Incorporar los elementos del contrato no estuvo exento de controversia, existiendo aquellos que planteaban la prescindencia de la causa, como ya lo hiciera hace más de cien años Planiol. Pero el grupo, como se indicó con anterioridad, optó por otorgar un lugar a ese elemento que, sin duda, florece en variadas instituciones y al cual corresponde un impulso para afirmar la utilidad técnica de la causa para revelar lo que algunos denominan el propósito práctico o la utilidad económica del contrato. Reitero acá la relación con la regla relativa a la frustración definitiva de la causa, en que se prefirió referirse a la "causa" en vez de a la "finalidad", pues lo que se buscó plasmar es una noción de causa entendida como el propósito práctico del contrato, alejada de los motivos subjetivos de las partes, permitiendo con ello una aplicación constante de la institución.

Otro aspecto que cabe considerar sería la causa en cuanto control del equilibrio, más allá de los vicios del consentimiento, que pasa a ser un mecanismo de control social de una mínima utilidad recíproca de las prestaciones contractuales. Es cierto que la función de la causa puede significar un concurso con otro tipo de justificaciones para la nulidad del acto. Sin embargo, no solo por el hecho de que haya un concurso desechamos las instituciones o descartamos su conveniencia. Lo mismo ocurre a propósito del error, que si bien en la región, de manera unánime, se entiende como un vicio del consentimiento, para varios autores cabe entenderlo como incumplimiento contractual, lo que abre la vía a la resolución del acuerdo, más que a la nulidad de este. De ahí la regla propuesta en el sentido de que, en caso de concurso entre las acciones a que dan lugar los problemas de formación y aquellas de incumplimiento, queden a elección del acreedor, siempre y cuando se satisfagan las condiciones. Así lo dispone el artículo 49: "Opción con los medios de tutela. La parte que tenga derecho a demandar la nulidad relativa del contrato y, al mismo tiempo, pueda ejercer alguno de los medios de tutela por incumplimiento, puede optar entre aquella y éstos".

Un asunto bastante pacífico fue la regulación del proceso de formación del consentimiento. Se regula el silencio como manifestación de voluntad, aunque se altera la denominada teoría del espejo, pues no solo la aceptación pura y simple da lugar a la perfección del contrato, sino que en el caso de adiciones o modificaciones que no se entiendan esenciales o más bien tengan un carácter marginal o accesorio, es posible considerar que se haya formado el contrato. Se decidió fijar el momento de perfección, para los contratos consensuales, en el momento en que la aceptación produce sus efectos (art. I3), lo que se aclara en el artículo 22: "en el momento en que la aceptación llega al oferente", acogiendo así la teoría de la recepción, salvo que la aceptación consista en una conducta, en cuyo caso es el momento en que el oferente la conoce, y por último, la posibilidad de que la aceptación emane de la ejecución de un acto. Otro aspecto que cabe destacar 
es la posibilidad de considerar como oferta aquella dirigida a persona determinada o aquella dirigida al público general (art. I 5). Mientras que en relación con la determinación del momento de aceptación de la oferta, como es usual, ya el silencio puede significar aceptación: "El silencio o la inacción, por sí solos, no constituyen aceptación, excepto en los casos en que la ley, la voluntad de las partes, los usos y prácticas, o los comportamientos precedentes de las partes, les otorguen tal carácter" (art. 2 I). Quizá, al menos en la región, una de las ideas novedosas consiste en romper con la teoría del espejo, como se indicó, al considerarse que si bien "[1]a respuesta a una oferta que contenga adiciones, limitaciones o modificaciones constituye una contraoferta", "si no alteran sustancialmente los términos de la oferta, la respuesta constituye una aceptación y el contrato se entiende perfeccionado con dichas adiciones, limitaciones o modificaciones" (art. 25). Con ciertos resguardos: “(3) Aunque las limitaciones o modificaciones no alteren sustancialmente los términos de la oferta, la respuesta se entiende como un rechazo si: (a) La oferta expresamente exige la conformidad total o parcial con los términos propuestos. (b) El oferente, sin demora, informa al destinatario su disconformidad con los cambios".

Cabe mencionar una cuestión ampliamente compartida en el derecho comparado, en el sentido de que se debe superar la idea decimonónica según la cual el error de derecho no vicia el consentimiento, no debiendo confundirse la presunción de conocimiento de la ley con la ignorancia acerca de una norma en el proceso de manifestación de voluntad (art. 28). En general se intenta avanzar en un sistema que permita un cierto equilibrio entre los intereses de las partes contratantes, cuyo norte, en lugar de conferir una excesiva protección al errans, le dé protección a la confianza que en forma legítima se haya generado entre las partes. Se excluye la clasificación tradicional del error entre esencial u obstáculo, sustancial, accidental y en la persona, sustituyéndola por otra que parte de las condiciones de relevancia y de inexcusabilidad del error, en el sentido de aquellas que determinan si la parte no hubiera contratado o lo hubiera hecho en términos sustancialmente distintos. Respecto al dolo, la novedad importante es que aun el dolo de tercero que induce a la celebración del contrato habilita a la nulidad del contrato, desechando la idea de que deba ser obra de una de las partes (art. 32). A su turno, la regulación de la fuerza o intimidación fue tomada o inspirada en el código civil peruano, cuyos textos recogen la idea de amenaza antijurídica de un mal inminente y grave. Y una propuesta de equilibrio contractual aparece a través de la regulación de la excesiva desproporción, conforme ya analizamos.

La cuestión de la nulidad es una de las más complejas y donde la nomenclatura es tan diversa como oscura. Sin embargo, varios de los países, que se dotaron de códigos una vez delineada la teoría de la nulidad, distinguiendo entre aquella que atañe al interés general -nulidad absoluta- y la otra que solo interesa a las partes -nulidad relativa-, la recogieron. Así aparece en el código chileno, colom- 
biano y aun en la propuesta argentina. Se mantiene prístina la distinción: ¿por qué cambiarla? Quizá debamos distinguir las causales que atienden al interés general de aquellas que sugieren más bien un simple problema entre particulares. ¿Qué justifica que al denominado error esencial u obstáculo se le asigne la sanción de nulidad absoluta, sin perjuicio de pensar que se trata de una categoría obsoleta, cuando en realidad nada tiene que ver ahí el interés general y la calificación de error sustancial es suficiente para abrigar las hipótesis usuales de lo que se conoce como error esencial? $\mathrm{O}$, en cuanto a los problemas vinculados al objeto ilícito, ¿qué razón para tratarlos como de interés público, en lugar de asignarles más bien la sanción de nulidad relativa? Con todo, el mayor dilema en ese ámbito fue el de si acoger una nulidad de naturaleza extrajudicial o, más bien, mantener aquella con acción ante el juez. Se impuso, como ya lo dije, la naturaleza judicial de la ineficacia intrínseca. Si bien para algunos esta respuesta estaba atada al problema de la resolución por notificación o extrajudicial, en opinión del grupo se trata de cuestiones diversas. Mientras la resolución constituye una situación de interés privado, la nulidad referida a los elementos de existencia y a la ilicitud de la causa pareciera que merece la mirada del juez para contrastarla con el interés general. En relación con los efectos de la nulidad y con el dilema de si concurre o no el efecto retroactivo o, si en cambio, este no es más que una ficción teórica, se repite el mismo problema a propósito de la resolución, lo que nos llevó a unificar los efectos de la nulidad y la resolución en un articulado común (arts. I I 9 ss.), salvo lo relativo al efecto extintivo (art. 50) y los efectos frente a terceros (art. 5I), dejando a salvo o protegidos solo a los terceros adquirentes a título oneroso y de buena fe, incluyendo, por último, la regla clásica de prohibición de restitución de lo que se hubiere dado o pagado por un objeto o causa ilícitos a sabiendas (art. 52).

\section{Cumplimiento e incumplimiento}

Respecto al cumplimiento, aparte de la definición ya entregada, merecen destacarse algunas reglas fundamentales ${ }^{\mathrm{Io}}$. En primer lugar, el artículo 80 , relativo al cumplimiento anticipado, que permite al deudor anticipar el cumplimiento, a menos que perjudique gravemente los intereses de la otra parte, y sin que eso altere las modalidades para el cumplimiento de ella. Y esto se corrobora con la facultad de renunciar al plazo que solo mire a su propio interés. En contrapartida, es posible la exigibilidad anticipada de la obligación por excepción, en caso de quiebra o notoria insolvencia, o de que "el deudor no haya constituido las garantías prometidas o éstas hayan disminuido, considerablemente, por un hecho que le sea imputable", y en aquella situación en la que "el plazo esté establecido

io Cfr. de la Maza, I., Pizarro Wilson, C. y Vidal Olivares, Á., Los Principios Latinoamericanos de Derecho de los Contratos, Madrid, Boletín Oficial del Estado, 2017. 
sólo en favor del acreedor”. Por último, se ratifica la posibilidad de que sea un tercero quien cumpla el contrato, "excepto cuando se hayan tenido en cuenta las condiciones especiales del deudor, o hubiere oposición conjunta del acreedor y del deudor".

Sin duda, es a propósito del incumplimiento y sus efectos que el grupo ha tenido las discusiones más álgidas. ¿Cuál debiera ser el modelo para regular el incumplimiento contractual? Como ya dijimos, el modelo por el cual se optó permite una sistematización necesaria de lo que se denomina los medios de tutela, sobre la base de una noción neutra de incumplimiento, pero con importantes resguardos destinados a un equilibrio necesario entre el deudor y el acreedor, todo bajo el manto del propósito práctico o finalidad del contrato. La sola mención de incumplimiento llevó al grupo a discutir acerca de la pertinencia de asociarlo a una cierta imputabilidad o culpa o, en cambio, privilegiar el incumplimiento como la mera insatisfacción del acreedor; dicho de otra manera, por el simple hecho de que el acreedor no reciba aquello a que tenía derecho estaríamos en presencia de incumplimiento, aunque la razón sea la fuerza mayor o la imposibilidad. La opción aparece, como se dijo, en el artículo 9o, que cabe relacionar con la definición de fuerza mayor del artículo 89.

En el sistema propuesto se pone el énfasis en delinear cuándo estamos en presencia de un incumplimiento esencial, lo que es relevante para la resolución del contrato, la suspensión del cumplimiento o la excepción de contrato no cumplido. Los trabajos académicos han ido decantando cuándo existe el incumplimiento esencial, y han descrito distintas hipótesis: cuando sea doloso; cuando se produzca la pérdida de la confianza del acreedor en razón de la conducta del deudor; o cuando no se pueda ya satisfacer el propósito práctico del contrato o no se ejecuta lo pactado en el plazo de subsanación reconocido al deudor en el artículo 93 .

Un asunto que tomó bastante tiempo fue el de cómo denominar al conjunto de posibilidades del acreedor frente al incumplimiento. Siguiendo una influencia del common law, o al menos así se ha entendido, con severos reparos doctrinales en el derecho francés, se proponía denominarlo "remedios contractuales". Esta expresión, irritante para algunos, también en Chile, fue desechada por aquella de "medios de tutela del acreedor", más neutra, aunque quizá menos expresiva. Y se desechó la expresión "sanciones", pues el fenómeno del incumplimiento no se asume como un asunto de reproche, sino que más bien se busca la solución a ese problema, intentando satisfacer el interés del acreedor.

¿Cuáles son esos medios de tutela? No solo la tradicional ejecución in natura, que aquí se denomina "cumplimiento específico", junto a la resolución y la indemnización de perjuicios, se recogen en este listado, sino que se agrega la rebaja del precio de la prestación y la excepción de contrato no cumplido, la cual se denomina "suspensión del cumplimiento", fijando su función única. Se desechó la propuesta argentina -sugestiva desde el punto de vista práctico, pero bastante 
difícil de incluir en los PLDC-, que distinguía como un medio de tutela aparte el cumplimiento por equivalencia o, lo que es lo mismo, el valor en dinero de la prestación. El tratamiento de los medios de tutela del acreedor fue ampliamente debatido por el grupo.

Respecto al cumplimiento específico, a pesar de lo propuesto por la doctrina tradicional, pierde su centralidad, siendo uno más entre los medios de tutela. Decae, en consecuencia, la idea de un principio de pervivencia del contrato. Más bien la procedencia de los medios de tutela tiene que ver con la satisfacción de las condiciones que habilitan para ejercerlos por el acreedor, siempre con el límite que impone la buena fe. De alguna manera la pertinencia de uno u otro medio de tutela no tiene que ver con una pretendida jerarquía entre ellos, sino con la satisfacción o no de sus condiciones. De ahí entonces que, por ejemplo, se haya establecido o propuesto como límite al cumplimiento específico, tratándose de obligaciones no dinerarias, no solo la imposibilidad, ya sea material o jurídica, o el clásico de las obligaciones personalísimas o intuitu personae -que repudian cualquier ejecución forzada contra la dignidad del deudor-, sino también cuando resultare extremadamente gravoso para el deudor, teniendo en cuenta que el acreedor puede satisfacer su interés con otro medio de tutela. No cabe confundir este asunto con la imprevisión, aunque la frontera sea tenue; en efecto, en esta no hay un incumplimiento generado por el deudor, por la conducta del deudor, sino que se trata de un hecho externo a él, imprevisto, que impacta en que la obligación resulte extremadamente gravosa en su cumplimiento.

En cuanto a la resolución, se propone que proceda por incumplimiento esencial y aun en caso de incumplimiento recíproco. Sin embargo, la novedad más relevante consiste en acoger una resolución por notificación extrajudicial. $\mathrm{El}$ acreedor, mediante una notificación, manifiesta su voluntad de poner término al contrato. En particular, no se acogió la idea, aunque discutida, de otorgar un plazo de gracia, sino que basta la notificación para que se entienda resuelto. Cabe recordar que resulta necesario un incumplimiento esencial para que prospere este medio de tutela, y se impone la idea de irretroactividad de la resolución, asumiendo que opera hacia el futuro, perviviendo las cláusulas establecidas precisamente para el caso del incumplimiento, por ejemplo, las cláusulas arbitral, penales, limitativas o exonerativas de responsabilidad, y además se unifican los efectos restitutorios con la nulidad, como se anunció, en los artículos i i 9 y siguientes. Se explicita un sistema detallado de restituciones, inspirado en gran medida en la propuesta española de modernización del derecho de las obligaciones y la reforma francesa ya vigente.

No solo se contempla la resolución por notificación, sino que se regula la resolución convencional, sin perjuicio de que pueda requerirse la resolución por vía judicial. Así queda propuesto un modelo de resolución de contrato que impulsa el acuerdo de las partes, y en caso de no haberse estipulado se da lugar a la resolución por incumplimiento esencial, quedando a salvo la resolución judicial. 
Respecto a la indemnización de perjuicios, hubo variados problemas que determinaron una propuesta simple e incluso minimalista. Se discutió si debían ampliarse las categorías de daños y reconocerse el carácter autónomo de la indemnización de perjuicios, y se determinó estipular la regla clásica de límite con base en la previsibilidad de los daños en materia contractual (art. Io7). Se aceptó incluir una regla relativa a la causalidad del acreedor en su propio daño, contemplada en el artículo ıo8: "La indemnización queda sujeta a reducción si el acreedor, con su acción u omisión, contribuyó a que se produjera el perjuicio”. Y, en términos bastante consensuados hoy, se admite la mitigación de perjuicios, debiendo reducirse la indemnización "si el acreedor no adopta las medidas que, de acuerdo con la buena fe, son razonables para mitigar el perjuicio". El deber, en consecuencia, se funda en la buena fe, pero se asocia a una regla de causalidad negativa o inversa, pues la "reducción corresponde a la cuantía en que hubiere podido mitigarse". También, en forma tradicional, se expresó: "El acreedor tiene derecho a la indemnización de lo que haya invertido en las medidas de mitigación, aun cuando éstas hayan sido infructuosas" (art. I09).

\section{Conclusión}

No se ha querido con este trabajo, ni mucho menos, dar una visión exhaustiva de los Principios, sino más bien mostrar sus aspectos más relevantes y, sobre todo, exhibir la formación y metodología de los mismos, con la esperanza de que, en el tiempo que sigue, permitan avanzar en debates necesarios y urgentes para esta materia esencial en la región latinoamericana.

\section{Referencias}

Beale, H. "The Principles of Latin American Contract Law: A reponse from an outsider", en The Future of Contract Law in Latin America. The Principles of Latin American Contract Law, Momberg, R. y Vogenauer, S. (eds.), Bloomsbury-Hart, 20 i 7.

Cafaggi, F. "Los nuevos fundamentos de la regulación privada transnacional”, en Revista de Derecho Privado [online], 2014, n. ${ }^{\circ}$ 26, I85-2 I 7, disponible en: http://www.scielo. org.co/scielo.php?script=sci_arttext\&pid=So I 23-436620 I 4000 I $00006 \& \operatorname{lng}=\mathrm{en} \& \mathrm{nr}$ $\mathrm{m}=$ iso [consultada el 30 de octubre de $20 \mathrm{I} 7$ ].

De la Maza, Í., Pizarro Wilson, C. y Vidal Olivares, Á., Los Principios Latinoamericanos de Derecho de los Contratos, Madrid, Boletín Oficial del Estado, 2017.

Genicon, Th., "Défense et illustration de la cause en droit des contrats, du régimen general et de la preuve des obligations", Dalloz, n. ${ }^{\circ} 27,2015$.

Kelemen, D. y Sibbitt, E. C. (2005). "Lex Americana. A reponse to Levi Faur”, disponible en: http://fas-polisci.rutgers.edu/dkelemen/research/kelemen-sibbitt_lexamericana.pdf 
Momberg, R. "The process of harmonisation of Private Law in Latin America", en The Future of Contract Law in Latin America. The Principles of Latin American Contract Law, Momberg, R. y Vogenauer, S. (eds.), Bloomsbury-Hart, 20 I 7.

Peña González, C., "La unificación de principios en el derecho latinoamericano", 20I4, inédito.

Pizarro Wilson, C. (coord.), El derecho de los contratos en Latinoamérica. Bases para unos principios de derecho de los contratos, Bogotá, Universidad del Rosario y Universidad Externado de Colombia, 20 I 2.

Rochfeld, J. Les grandes notions du droit privé, Paris, Thémis droit-PUf, 20 I I. 